\title{
Research on High-frequency induction brazing of PCD Cut Tool Bei Sun ${ }^{\mathrm{a}, 1}$, * Miao Yang ${ }^{\mathrm{b}, 2}$, Zhiyi Zhang ${ }^{\mathrm{c}, 2}$ \\ ${ }^{1}$ College of Mechanical and Engineering, Beihua University, Jilin, 132021, China \\ ${ }^{2}$ Engineering Training Center, Beihua University, Jilin, 132021, China \\ aemail: 1512974922@qq.com, *corresponding \\ writer bemail:yangmiao1021@163.com,'email:zyzhang6@163.com
}

Keywords: high frequency induction brazing; Brazing filler alloy; PCD compact; microstructure

\begin{abstract}
The morphologies of the brazing fill are studied by SEM and EDS. The binding force and use life of PCD cut tool are studied too. The results shows that the quality of weld fill is the best when time is 13 and 15s. Meanwhile, the weld fill shows metallurgical bond. The Interdiffusion of matrix alloy and weld fill helps to improve the mechanical properties of the brazed fill.The overheat from long time of high frequency will cause the PCD carbonization, which shorten the use life of the tool.
\end{abstract}

\section{Introduction}

As a proper material for cutting graphite electrodes, the PCD cutting tool is widely used due to its high hardness, high wear-resistance and high intension of hard alloy[1]. The PCD cutting tool is composed of PCD compact and base material. Usually, it can be obtained by means of brazing with proper brazing filler alloy, soldering flux, a certain PCD compact and base material, then grinded with several methods. The high-frequency induction brazing is commonly used in the brazing of PCD compact recently[2-5]. As it is well known, high frequency induction heating is efficiency and high speed. So, brazing time has a significant impact on the PCD tool life.

\section{Experimental procedures}

The experiment is actually the brazing between 45\# steel and carbide alloy, which is the bottom sheet of the PCD compact. The components of experimental brazing filler were detected by ICP-AES and list in Table 1. The carbide alloy is mainly composite of WC. The high-frequency equipment is WH-WI-26. The chemical compositions of soldering flux were list in Table 2 .Before welding, the two material were filed with the rasp in order to improve the welding strength. Then the samples were washed with ethanol in ultrasonic cleaning machine. The welding time is $7,9,11,13$, $15,17,19 \mathrm{~s}$. The shear force measurement was used for characterize of weld strength. The use-life of the PCD-knife was measured by machining carbon electrode. And everyday machining time is 7 hours. The microstructure of the welds were recorded and analyzed by JSM-5600 SEM equipment.

Table 1 compositions of experimental brazing filler

\begin{tabular}{|c|c|c|c|c|c|c|c|c|}
\hline \multirow[b]{2}{*}{$\begin{array}{c}\text { Composition } \\
\text { (wt.\%) }\end{array}$} & $A g$ & $C u$ & $Z n$ & $\mathrm{Ni}$ & Co & $C d$ & Melting- & point \\
\hline & 48.7 & 15.6 & 15.5 & 1.2 & 1.8 & 19.2 & 750 & ${ }^{\circ} \mathrm{C}$ \\
\hline \multicolumn{9}{|c|}{ Table 2 chemical compositions of soldering flux } \\
\hline Comp & itions( & & $\begin{array}{c}\text { KF } \\
42 \\
\end{array}$ & & & & $\begin{array}{l}\mathrm{O}_{3} \\
5\end{array}$ & \\
\hline
\end{tabular}

\section{Results and discussion}

\section{A. Weld}

Figure 1 shows the SEM morphologies of the weld fills which the brazing time is $13,15,17 \mathrm{~s}$ separately. From Figure 1(a), the weld fill is well combined with the steal side, though it has some 
pores. In Figure 2 (b) and 2(c), both the weld fills are smooth and without cracks, pores or inclusions. From Figure1, the base material and the meld fills are metallurgical bonding and the combination surface are closely tight. The intragranular diffusion appears between weld and base material. The Ag, Cu, Zn, Co in the meld become to solid solution.

Figure 2 shows the EDS results of brazing time 13s. From bottom to top, there are carbide (WC), weld fill(Ag, $\mathrm{Cu}$ ) and 45\# steel(Iron). The microstructure of the weld fill appears boundary diffusion. That means at the brazing time of 13s, the heating of the high-frequency magnetic field make the both sides of the weld melted and combined. When material is heated by high-frequency magnetic field, the eddy current as follow[6]:

$$
I_{x}=I_{0} e^{-\frac{1}{\delta} x}
$$

$I_{x \text {--the current at the distance } \mathrm{x} ;} I_{0}$--the current at the top; $\delta$--the modulus of frequency and the physical properties of materials.

At the distance of $1 / \mathrm{e}(=0.368)$, the $\delta$ called skin depth.

$$
\delta=5.03 \times 10^{4} \sqrt{\frac{\rho}{\mu f}}
$$

$\rho$---the electrical resistivity; ${ }^{\mu}$---the magnetic permeability; $f$---the frequency of the electricity.

In the heating process, when the temperature of the steel is reach to $800 \sim 900{ }^{\circ} \mathrm{C}$, $\rho \approx 10^{-4} \Omega \cdot \mathrm{cm}, \mu \approx 1 T$, then

$$
\delta=\frac{503}{\sqrt{f}},
$$

the frequency of the equipment is $300 \sim 500 \mathrm{KHz}, \delta=0.7 \sim 0.9$ (mm). So, the heating depth in this research is less than $0.9 \mathrm{~mm}$.

Figure 3 shows the EDS results of the carbide and weld fill of brazing time 15s. Meanwhile, Figure 4 shows the EDS results of the 45 \# steel and weld fill of brazing time 15s. From Figure 3 and 4 , the material of weld and the base alloys both occurs mutual dissolution. The amount of base alloys dissolved is list as[4]:

$$
G=\rho C \frac{V}{S}\left(1-e^{-\frac{\alpha S t}{V}}\right)
$$

$G$--the amount of base alloy dissolved per unit area; $\rho$--the density of liquid brazing fill; $V$-the volume of liquid brazing fill; $S$--the contact area of liquid and solid; $\alpha$-- the solubility coefficient of the base material in liquid brazing fill; $t$-- the time of contact.

The amount of base alloy dissolved would changed the composition of the brazing fill, which improved its strength and hardness. According to formula 2.4, the increasing of the volume of liquid brazing fill, temperature and the solubility limit would leaded to increasing the base alloy dissolved excessively. So, proper process parameters should be chosen to avoid over dissolving of base alloy.

Otherwise, the material in brazing fill also move to the base alloy. According to diffusion law[7]:

$$
D_{m}=-D S \frac{D_{c}}{D_{x}} d t
$$

$D_{m}$--The amount of brazing fill diffusion into base alloy; D-diffusion coefficient; S-diffusion area; $\frac{D_{c}}{D_{x}}$--concentration gradient; $d t$--diffusion time.

From formula (5), in this experiment the temperature is the most important factor. And the temperature is straightly to the use time of the high frequency. In this study, the weld time was chosed from 11 to $15 \mathrm{~s}$, which would get proper fusion heat. 

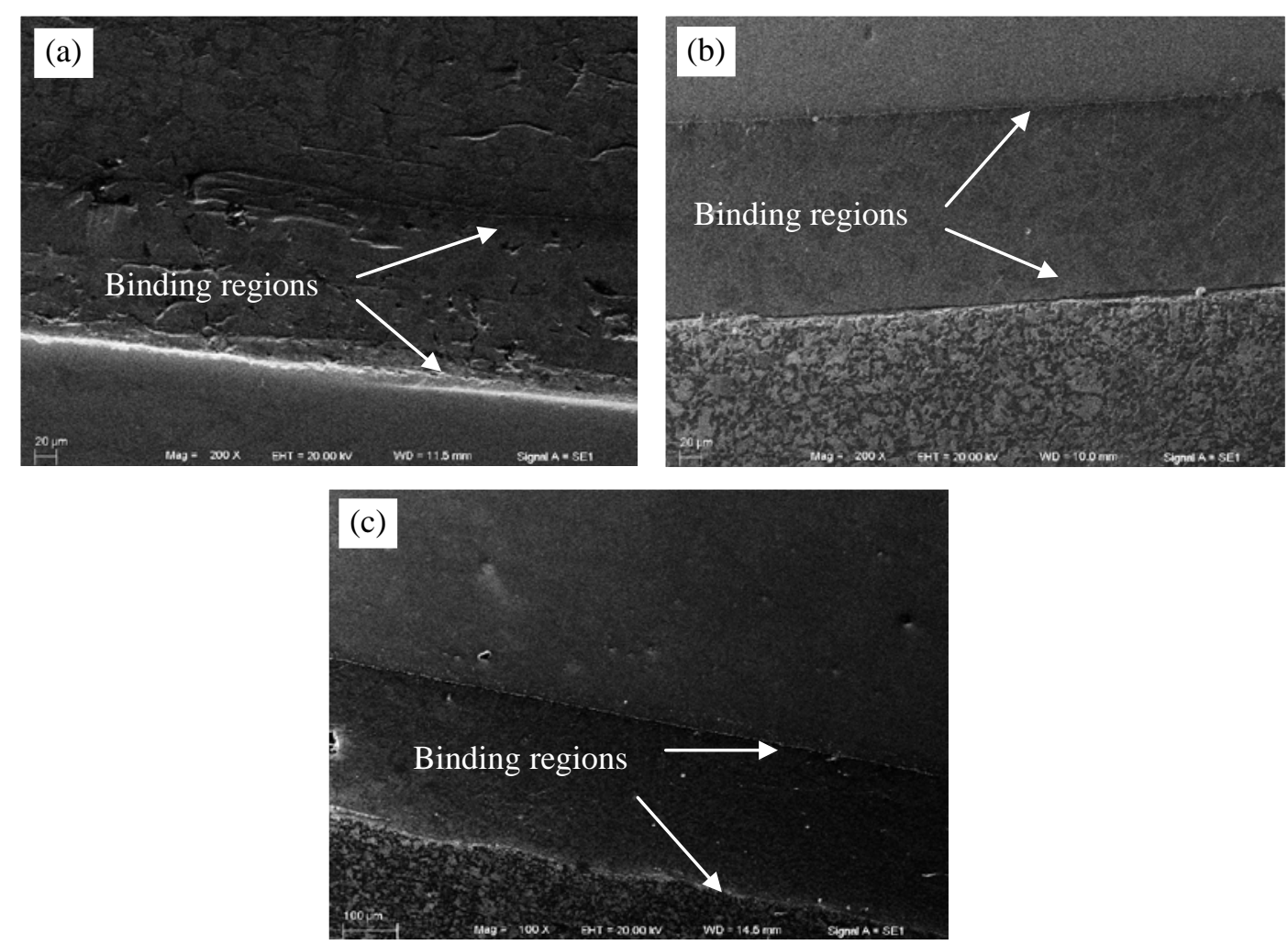

Figure 1 The SEM morphologies of brazing time 13s (a),15s (b) and 17s (c).
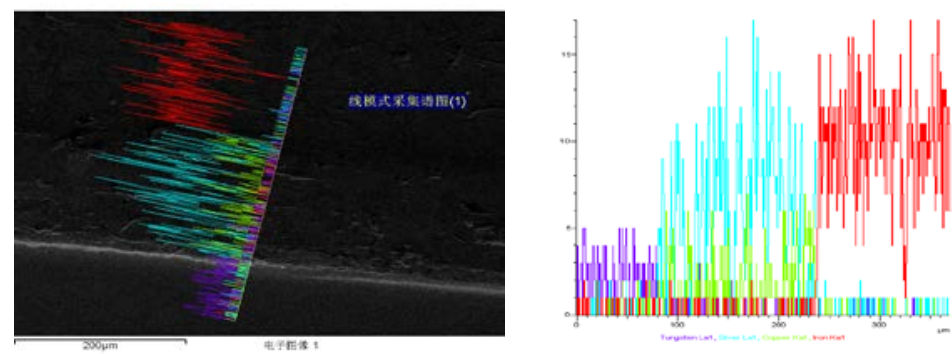

Figure 2 The EDS results of the brazing time 13s.
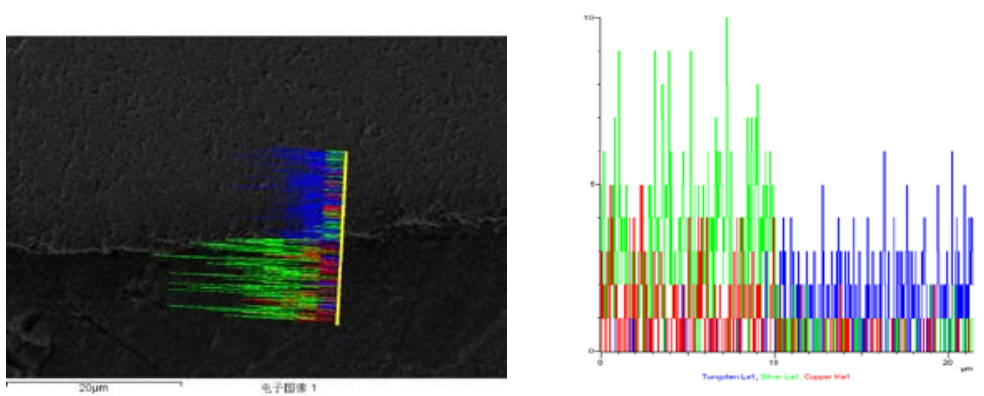

Figure 3 The EDS results of the carbide and weld fill of brazing time 15s . 

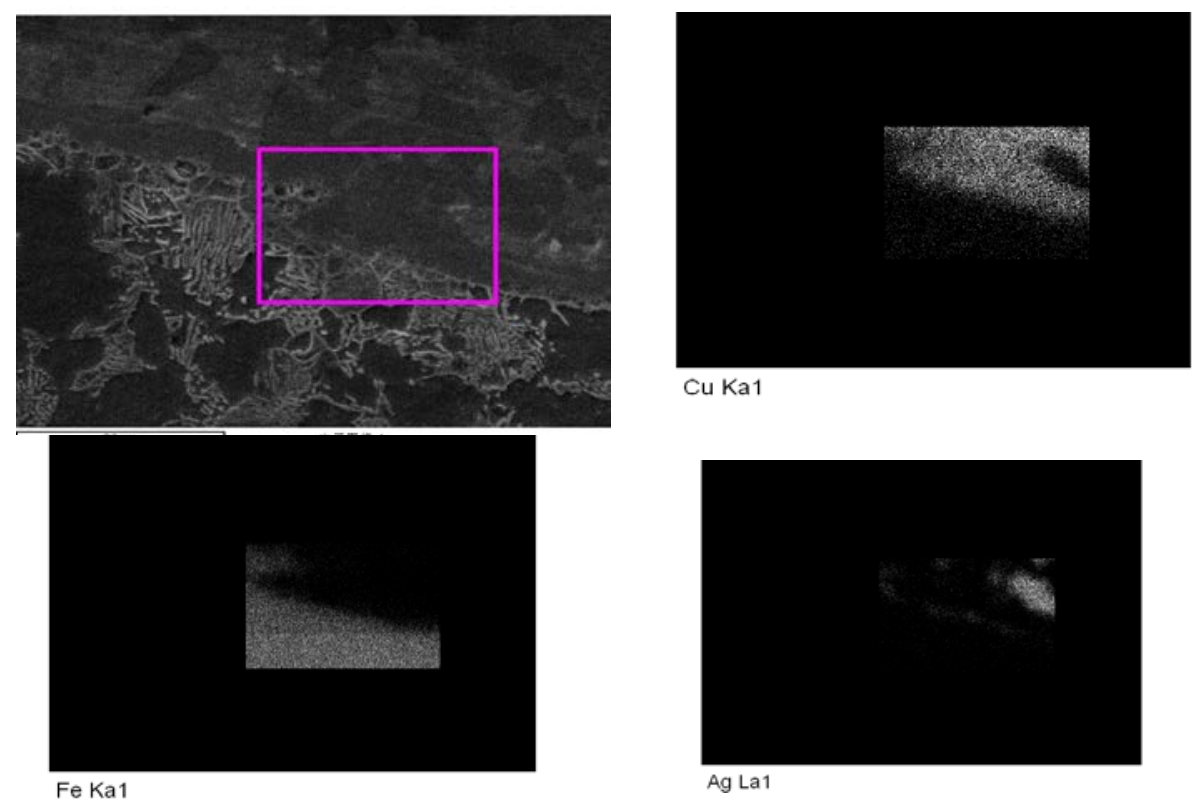

Figure 4 The EDS result of $17 \mathrm{~s}$

\section{B. Welding Strength}

The strength of the weld with brazing time is shown in Figure 1. The strength of weld increases with brazing time till 15s, then decreases. Due to the skin effect of the high frequency induction heating the welding flux at the welds melts first. Then the inside of the welds melts rely on conduction heating. With the increasing of the brazing time, the temperature of the sample increases with high speed. The Ag, $\mathrm{Cu}, \mathrm{Zn}, \mathrm{Ni}$, Co and $\mathrm{Cd}$ in the brazing fill melted and became to solid solution. The molten state of brazing fill the weld gap by capillary action. Meanwhile, the base metal dissolved into the brazing fill during the brazing process. The strength of the brazing fill shows that the heat of the high-frequency induction is benefit to improve the binding force of the steel and carbide in 15s. The along with the heating time, the composition of the weld fill turned to be destroyed by the excessive heat.

C. Use- life

Figure 6 shows the use life along with the brazing time. The use life increased with brazing time till 15s, then decreased. When time increased to 19s, the use life dropped to just 6 hours. The use life was about the PCD cutting life for carbon electrode. Though the study focus on the weld fill, the final aim was to produce PCD cut tool. Form the analysis of the weld fill, the fusion heat not only influence the quality of the weld fill but also the PCD use life. $C$ is the main element in PCD, the excessively high temperature would lead the PCD to carbonized and become invalid. That is seriously issue to consider. In this study, it should be as short as possible to determine the welding time. Combine Figure 5 and 6 , the proper welding time is $15 \mathrm{~s}$.

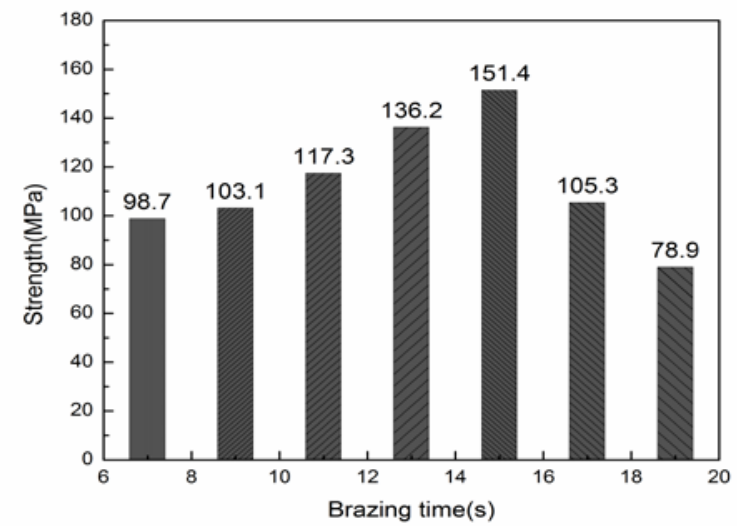

Figure 5. The strength of the weld fill with brazing time 


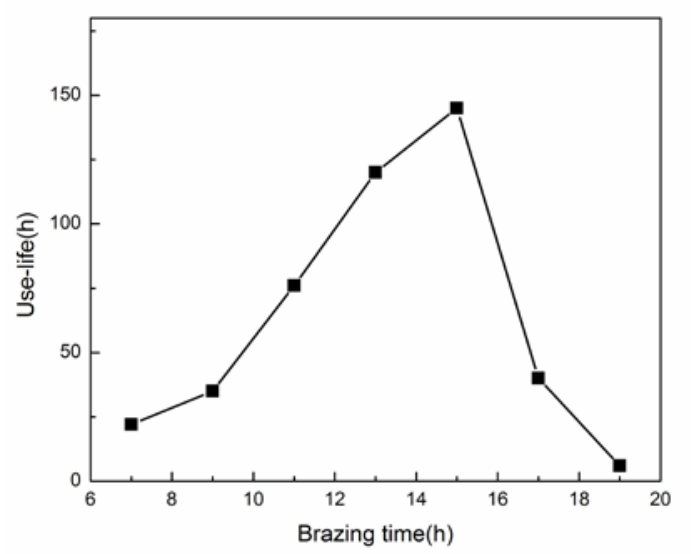

Figure 6. The use-life of the weld fill with brazing time

\section{Conclusion}

The brazing fill of steel and carbide alloy on PCD knife is studied. The conclusions are as follows:

1). The quality of weld fill is the best when time is 13 and 15s. Meanwhile, the weld fill shows metallurgical bond.

2) The Interdiffusion of matrix alloy and weld fill helps improve the mechanical properties of the brazed .

3)The overheat from long time of high frequency will cause the PCD carbonization, which shorten the use life of the tool.

\section{Reference}

[1] Bigelow L K, Chen S H, Merrill L, et al. Low pressure bonding of PCD bodies and method for drill bits and the like: U.S. Patent 4,943,488[P]. 1990-7-24.

[2] Bigelow L K, Kapoor R R, Nagy B G. Brazing of diamond film to tungsten carbide: U.S. Patent 5,738,698[P]. 1998-4-14.

[3] Chunn G R, Johnson M A, Keith C W. Brazing receptacle for improved PCD cutter retention: U.S. Patent 5,737,980[P]. 1998-4-14.

[4] Bigelow L K, Chen S H, Merrill L, et al. Low pressure bonding of PCD bodies and method: U.S. Patent 5,030,276[P]. 1991-7-9.

[5] Weimin L. Research on the Brazing Alloy and Brazing Technology for PCD [J]. Diamond \& Abrasives Engineering, 2002, 4: 007.

[6] M. W. Cook. Wear-resisting properties and application examples of PCD. Industrial Diamond Review,1996,4:107-111.

[7] Rongchao J. Some Practical Means for improving Diamond Tool Quality [J]. Diamond \& Abrasives Engineering, 2001, 4: 004. 